\title{
Advances in Office Anesthesia
}

\author{
Edward G. Whealton, $M D$
}

Background: Recent developments in anesthesia applicable to family practice settings are reviewed.

Methods: MEDLINE was searched using the key words "EMLA"; "iontophoresis"; "lidocaine," "tetracaine, adrenaline, cocaine"; and "lidocaine, epinephrine, tetracaine."

Results and Conclusions: Clinical experience has shown that there is a definite and evolving role for the newer methods of office anesthesia. Patient care can be improved by reducing the discomfort of patient procedures. (J Am Board Fam Pract 1998;11:200-6.)

The goals to minimize patient discomfort and improve patient satisfaction during office procedures have brought about some new and innovative anesthesia techniques. I will review some of the newer developments that can be utilized in primary care.

\section{Methods}

A MEDLINE search of medical literature from 1986 to present was used to select clinical studies, case reports, and review articles. The specific terms investigated were "tetracaine, adrenaline, and cocaine"; "lidocaine, epinephrine, and tetracaine"; "EMLA"; and "iontophoresis." Other artcles and textbooks were cross-referenced from the endnotes of articles. Personal communication with Naval Medical Center Portsmouth pharmacy personnel was used to document pertinent national, state, and armed forces regulations. Only articles in English were reviewed.

\section{Lidocaine}

Lidocaine infiltration has remained the standard of care for local anesthesia for lacerations, although the pain on injection has caused difficulty with patient acceptance. Recently lidocaine has been studied to find out whether patient acceptance could be improved by warming and buffering.

Lidocaine has a $\mathrm{pK}_{\mathrm{a}}$ of 7.9. ${ }^{1}$ Lidocaine, particularly lidocaine with epinephrine, is sold at a $\mathrm{pH}$ as

Submitted, revised, 30 July 1997.

From the Department of Family Medicine, Naval Medical Center, Portsmouth, Virginia. Address requests for reprints to Edward G. Whealton, MD, 160 Sir Oliver Road, Norfolk, VA 23505.

The views represented here reflect the views of the author and not those of the Department of Defense or the United States Navy. low as 3.82 to improve shelf life. ${ }^{2}$ Buffering lidocaine with bicarbonate raises the $\mathrm{pH}$ and effectively increases the concentration of nonionized lidocaine, which is the active form. An increase in the $\mathrm{pH}$ of lidocaine from 6 to 7 would increase the concentration of the active form from less than 1 percent to 11 percent. ${ }^{3}$

Several experiments have been done using buffered lidocaine, usually buffered with sodium bicarbonate in a 1 to 9 concentration (1 part sodium bicarbonate to 9 parts lidocaine). The concentrations of sodium bicarbonate have varied from 7.4 percent $(44 \mathrm{mEq} / 50 \mathrm{~mL}$ ) to 4.2 percent $(25 \mathrm{mEq} / 50 \mathrm{~mL})$. In one experiment, the dilution was 1:10. Buffering lidocaine has been shown uniformly to reduce injection pain..$^{4,5}$ Additionally, warming the lidocaine to $98^{\circ} \mathrm{F}$ to $104^{\circ} \mathrm{F}$ has been shown to offer comparable but not superior improvement in pain reduction when compared with buffered lidocaine. Both buffering and warming lidocaine give a result superior to either buffering or warming alone. 6,7 The only study that examined lidocaine with 1 percent epinephrine and mepivacaine found buffering reduced injection pain for both. ${ }^{4}$ Buffered lidocaine reduced pain on injection with digital blocks. ${ }^{8}$ The few studies that examined plain lidocaine versus buffered lidocaine for effectiveness of anesthesia found no difference. $5,6,8$

The trade-off for buffering lidocaine is a diminished shelf life. The maximum shelf life of buffered lidocaine has not been experimentally proved. One study found buffered lidocaine to be effective 1 week after buffering. The same experiment showed no difference in effectiveness and duration of anesthesia when compared with an unbuffered lidocaine, but found the lidocaine concentration 
decreased from 90 percent to 80 percent at 7 days. ${ }^{9}$ Another study found that buffering lidocaine and epinephrine combined and storing it at room temperature reduced the lidocaine concentration to 66 percent and epinephrine to 1 percent of their original concentrations at 4 weeks. When the same compounds were stored at $4^{\circ} \mathrm{C}$, the 4-week concentrations of lidocaine and epinephrine were 95 percent and 82 percent, respectively. ${ }^{1}$ An additional study found a reduced duration of lidocaine anesthesia effectiveness, ${ }^{10}$ though whether this reduction is clinically important has not been established. The clinical trials have yet to cite a need for further anesthesia while using buffered lidocaine when compared with unbuffered lidocaine. ${ }^{5,6,8,9}$

In conclusion, it is possible to get the same effectiveness of lidocaine without nearly the pain by buffering or warming the lidocaine. The potential benefit for many procedures is great. Lidocaine is inexpensive, even with a shortened shelf life. The lidocaine could be buffered at the times of use to minimize cost and concern about monitoring its effectiveness after buffering.

\section{Tetracaine, Adrenaline (Epinephrine), and Cocaine}

In 1980 Pryor et a ${ }^{11}$ first showed that a combination of tetracaine, adrenaline (epinephrine), and cocaine (TAC) was effective as local anesthesia for lacerations. TAC, a compound of 0.5 percent tetracaine, 0.05 percent epinephrine, and 11.8 percent cocaine, is not sold as a set compound but is formulated by local pharmacies. It is used by soaking a cotton pledget or gauze with 2 to $10 \mathrm{~mL}$ of the solution and applying it to the wound..$^{12} \mathrm{Al}$ though application times in studies vary from 5 to 30 minutes, the one study that addressed application time found 30 to 40 minutes to be most effective. ${ }^{13}$ Dosing standards are variable and not uniform, ${ }^{14}$ but a general rule, which has been used in some studies, is $5 \mathrm{~mL}$ for a $3-\mathrm{cm}$ laceration and an additional $5 \mathrm{~mL}$ for a laceration greater than 3 $\mathrm{cm} .{ }^{11}$ Another dosage is $1 \mathrm{~mL} / \mathrm{cm}$ of laceration. ${ }^{15,16}$

The major benefit of TAC is that it offers the possibility of painless anesthesia, which is especially advantageous in the pediatric population. Additionally, it could minimize wound distortion from injection. TAC has not been used in studies on the penis, digits, nose, or ear because of its intense vasoconstrictive effects. In a ground-breaking effectiveness study comparing TAC with lidocaine infiltration, Pryor et al ${ }^{11}$ found TAC to be as effective as lidocaine. Moreover, patient-parent acceptability was considerably greater in the younger than 17-year age-group. Their study, however, did not examine results by laceration location.

Subsequent studies have shown mixed results regarding anesthesia effectiveness for facial and scalp compared with extremity and trunk lacerations. Anderson et $\mathrm{al}^{17}$ found no difference between TAC and lidocaine in effectiveness based on laceration location but did find a statistically significant difference when comparing both TAC and lidocaine with placebo on the face and scalp. Nevertheless, neither TAC nor lidocaine was significantly better than placebo on the extremities. Hegenbarth et a ${ }^{18}$ found 81 percent effectiveness on facial and scalp wounds for TAC compared with 87 percent for the lidocaine-treated group, a difference that was significant. Additionally, the effectiveness of TAC and lidocaine on the extremities was 43 percent and 89 percent, respectively. Eighty-eight percent of the parents of children whose facial and scalp lacerations were treated with TAC were satisfied compared with only 75 percent of parents of children with trunk and extremity wounds treated with TAC. The authors concluded that the TAC was effective on the face and scalp but not on the extremities. Smith and Barry, ${ }^{16}$ Ernst et al, ${ }^{19}$ and White et al ${ }^{20}$ also found that TAC was less effective on nonfacial wounds.

There have been few data regarding age and effectiveness of TAC. Pryor et al, ${ }^{11}$ in their original study, found no difference in acceptability between TAC and lidocaine infiltration in patients 17 years of age or older. Subsequent studies comparing TAC with lidocaine controlled for age but did not analyze effectiveness by age. One study did document a significant age difference between those with extremity and trunk lacerations and those with facial and scalp lacerations. TAC was much less effective on the trunk and extremity lacerations. ${ }^{18}$

The original composition of TAC was somewhat arbitrary and experiments have been performed to determine whether adjusting the components to reduce potential toxicity would be possible. Cocaine with adrenaline alone was found not to be as effective as TAC by one author and equivalent by another author. ${ }^{19,21}$ White et a ${ }^{20}$ and Schaffer ${ }^{22}$ both found TAC superior to tetracaine and adrenaline alone on the face. Bonadio and 
Wagner ${ }^{23}$ found half-strength TAC to be effective on facial lacerations but did no comparison with regular TAC. Two less potent TAC formulations were used and found to be as effective as standard TAC on facial lacerations. ${ }^{17}$

Each milliliter of TAC contains $5 \mathrm{mg}$ of tetracaine, $0.5 \mathrm{mg}$ of adrenaline, and $118 \mathrm{mg}$ of cocaine.Severe toxicity with TAC has occurred, but rarely. There have been two deaths attributed to TAC. One occurred when TAC was used directly on the tongue; status epilepticus and cardiopulmonary arrest quickly ensued. ${ }^{24}$ The second occurred when a child had a laceration repaired between the vermilion border and the nare. She was seen licking her lips, and some solution was noted to drip in her nose. After discharge, the child was found dead 3 hours later. Her cocaine and cocaine metabolite level was $11.9 \mathrm{mg} / \mathrm{L}$, which is a lethal level. ${ }^{25}$ In both of these cases, rapid absorption from the mucosal surfaces was believed to be the reason for toxicity.

Other systemic side effects of TAC include seizures, which are a known complication of a cocaine or tetracaine overdose. In one case, TAC was applied to burns of a 15-month old girl, and seizures began 2 to 3 minutes later. ${ }^{26}$ Another instance occurred when TAC was placed over the buccal mucosa of a 5-year-old child. The child appeared abnormal after 2 minutes, then aspirated the pledget into the posterior pharynx while fighting the mother; 10 minutes later the child was having a seizure. ${ }^{27}$ Similar circumstances occurred in a 6-year-old child with a palatine laceration and a 6-month-old infant with a mucosal laceration. ${ }^{28}$ Less severe, generalized disorientation and agitation occurred when TAC came inadvertently into contact with mucosal surfaces. ${ }^{29}$ TAC caused a dilated pupil and corneal abrasion when mistakenly held over the eye instead of the eyebrow. ${ }^{30}$ Historically, cocaine was discontinued as an ophthalmic topical anesthetic, because sloughing of the corneal epithelium commonly occurred. ${ }^{31}$

Theoretical concerns have been raised regarding wound healing and infection rates with TAC because of its intense vasoconstriction. One study found that wounds in guinea pigs treated with TAC and purposely contaminated with Staphylococcus aureus had significantly more infections than those treated with normal saline. In the same study, lacerations were injected intradermally with $S$ aureus suspended in either tetracycline and cocaine, tetracycline alone, cocaine alone, TAC, or normal saline used as a control. The TAC, cocaine, and tetracaine and cocaine groups had more infection compared with saline and tetracaine by itself. ${ }^{32} \mathrm{~A}$ similar laboratory study found no increase in quantitated bacterial counts in pig lacerations contaminated with $S$ aureus when treated with TAC compared with lidocaine. ${ }^{33}$ The clinical studies on humans in which wound management was practiced comparing TAC with lidocaine have not shown any significant increase in wound infections. ${ }^{11,19}$

Absorption of cocaine after TAC application to a lacerated dermis does occur. It was noted in 75 percent of patients, but at levels not believed to be serious. ${ }^{34}$ Urine tests for cocaine metabolites can be positive 2 days after TAC use. ${ }^{35}$ Patients who are in professions in which routine drug testing occurs need to be warned.

The final drawback to using TAC is the necessity of storing it to meet the legal requirements. At our facility, military, state, and Drug Enforcement Administration regulations require cocaine to be stored in a double vault, be subject to perpetual inventory, have inventory records kept for 2 years, and have regular inventories to monitor records (Michael Harris, CAPT, Outpatient Pharmacy, NMC, Portsmouth, Va, 26 March 1998, personal communication).

In conclusion, TAC can be both safe and effective in facial and scalp lacerations. Extreme care must be given to ensure that it is applied directly to the wound, and it should not be used on mucosal surfaces or burns. Its efficacy in adults might not be as great as in children. Its use is best facilitated by being in close contact with a pharmacy that can meet the legal requirements to store it, as use in a private office would require the acquisition of a dispensing license.

\section{Lidocaine, Epinephrine, and Tetracaine}

Combining lidocaine, epinephrine, and tetracaine (LET) is a recent attempt to make a topical anesthetic with less toxicity and less cost than TAC. The cocaine, which is assumed to be the toxic component, has been replaced by lidocaine. The application technique is similar, but optimal application times have not been clinically defined.

Only a few studies using LET have been published, and these evaluated the efficacy of LET on only face and scalp lacerations. Lacerations of the 
ear and nose were excluded. The effectiveness of LET (lidocaine 4 percent, epinephrine 0.1 percent, tetracaine 0.5 percent) was judged against TAC, not lidocaine infiltration, in a double-blind study. Both the duration and adequacy of anesthesia were found to be not statistically different. Study patients were aged between 0 and 17 years, and no obvious effect of age was observed. ${ }^{36} \mathrm{~A} \mathrm{sec-}$ ond study using a different formulation (lidocaine 4 percent, epinephrine 0.2 percent, and tetracaine 1 percent) found no significant difference between LET and TAC in patient perception of pain and percentage of sutures placed with pain. ${ }^{37}$

The place of LET and its clinical profile are still evolving. It might indeed offer a safer alternative to TAC but will probably be used with the same restrictions. Seizures have also been reported from a 2 percent lidocaine jelly that was applied to burns covering 15 percent of the body surface of a 20month old child. ${ }^{26}$ Mucosal absorption should be as rapid as with TAC and should therefore result in potential toxicity. Storage and monitoring concerns could make it more practical for use in most offices.

\section{Eutectic Mixture of Local Anesthetics - EMLA}

EMLA is an abbreviation of eutectic mixture of lo$\mathrm{cal}$ anesthetics. It is a compound formed by combining $25 \mathrm{mg} / \mathrm{mL}$ of lidocaine, $25 \mathrm{mg} / \mathrm{mL}$ of prilocaine, a thickener, an emulgent, and distilled water with $\mathrm{pH}$ adjusted to 9.4 . It is applied in a thick layer, covered with a patch (Tegaderm), and usually left on for 30 to 60 minutes. The effectiveness of anesthesia will increase during the 30 to $60 \mathrm{~min}$ utes after removal. ${ }^{38}$ The application can result in pallor and then erythema of the affected skin. It has not been studied in human lacerations.

Systemic toxicity from EMLA is extremely rare. Monitored absorption levels of prilocaine and lidocaine from EMLA have been in the low 100 $\mathrm{ng} / \mathrm{mL}$ range; lidocaine toxicity occurs at 3 to 5 $\mu \mathrm{g} / \mathrm{mL} .{ }^{39}$ The major concern regarding toxicity is formation of methemoglobin. This side effect has been reported only once. A 12-week old boy on a sulfonamide developed a brownish color caused by a methemoglobin level of 28 percent after a prolonged application of EMLA. He was treated with methylene blue without adverse sequelae. Methemoglobin levels above 30 percent can produce systemic compromise. It is believed that this unusual clinical occurrence was secondary to an age-related immaturity of the enzyme that converts methemoglobin to hemoglobin and the concomitant treatment with sulfamethoxazole, which also placed the patient at risk for methemoglobinemia. ${ }^{40}$ Subsequent studies have shown EMLA to increase concentration of methemoglobin in infants 6 months old and younger, although not to a clinically important level. ${ }^{41}$ At present it is best not to use EMLA on infants younger than 6 months who are also taking nitrates, sulfonamides, primaquine, or other medications that cause methemoglobinemia.

The only other reported major side effect has been contact dermatitis, which is rare. When tested, the dermatitis appeared to be secondary to prilocaine. ${ }^{42}$ Irritation from the Tegaderm patch has also been noted. ${ }^{38}$

The effectiveness of EMLA is based on its ability to penetrate intact skin and block pain. Its anesthetic effect has been shown to reach a depth of 5 $\mathrm{mm}$ after a 120-minute application. In several patients who had EMLA for anesthesia, needle sticks penetrated to the fascia without pain. ${ }^{43}$ This depth allows for painless curettage of molluscum. ${ }^{4+-46}$ Treatment of condylomata acuminata was successful in men after a 30-minute application, but it was only 40 percent effective in women. ${ }^{47}$ Subsequent response for vulvar condylomata improved after the application time on the genital mucosa was changed to 5 to 10 minutes. There was a progressive decrease in effectiveness after a 10-minute application time on the vulvar mucosa. ${ }^{48-49}$ These studies involved multiple modalities-laser, cautery, and, less frequently, excision. ${ }^{47-49}$

Experience reported in the literature for other uses of EMLA is very broad but not deep. EMLA has been shown to be useful in a variety of primary care procedures, including superficial biopsies. Anesthesia was not adequate for deeper biopsies. ${ }^{44}$ Neonatal circumcision was much less painful and improved oxygen saturations resulted when using EMLA compared with placebo. ${ }^{50}$ Pain during vasectomy procedures diminished considerably only when EMLA was used in addition to local anesthetic infiltration. ${ }^{51}$ There is one report of painful external otitis treated with EMLA application for 1 hour. The symptoms improved, and further cleaning of ear by suction was made easier. ${ }^{52}$ One case of vertigo caused by EMLA in the external auditory canal has been reported. ${ }^{53}$ Refractory postherpetic neuralgia was relieved after a 24-hour application. Long-term use brought continued relief, but there 
were no suggestions for frequency and duration of dosing. ${ }^{54}$ Vaccination pain was reduced, but not eliminated, after applying EMLA for 60 minutes. ${ }^{55}$ EMLA reduced response to pain from heel lancing in preterm infants, but not in term infants. ${ }^{56,57}$ EMLA has been beneficial in venipuncture, lumbar puncture, and arterial catheterization, as well as many plastic surgery applications. ${ }^{58,59}$

When EMLA is applied to atopic or psoriatic skin, its anesthetic effect is quicker, and there are higher, but less than toxic, levels of the lidocaine and prilocaine in the circulation. Anesthesia effect is noted after 15 minutes and resolves quickly. ${ }^{60}$ One would want to consider the quicker time from application to procedure if dealing with a patch of atopic or psoriatic skin. As noted above, mucosal surfaces are anesthetized in 5 to 10 minutes. ${ }^{49}$

EMLA offers a potential anesthetic agent that can be used on intact skin and mucosa for a variety of procedures. The drawback is that 1 hour of application might be necessary to achieve benefit, with an additional hour of waiting. This can be dealt with by planning. It certainly offers potential to improved patient tolerance of certain common procedures. EMLA is still being investigated in many settings, and its evolving role is yet to be completely defined. Pediatric and other hospital nursing units are probably using it already. If not, it would be valuable to check to ensure that these units are aware of the benefits of using EMLA. It would be easy to implement using EMLA in a private office.

\section{Iontophoresis}

Iontophoresis is a relatively new technique for anesthesia of intact skin. A small current is applied to lidocaine-soaked sponges. The concentration of lidocaine appears not to be important; 4 percent lidocaine was as effective as 50 percent. Duration, however, is important; a 10 -minute duration was significantly more effective than 5 minutes in reducing pain scores. ${ }^{61}$

The effectiveness of iontophoresis has been compared with EMLA. One study found that iontophoresis was more effective than EMLA after 30 to 60 minutes of application. ${ }^{62}$ Iontophoresis permitted painless needle insertion to an average depth of $6.0 \mathrm{~mm}$ compared with $4.4 \mathrm{~mm}$ for EMLA $^{63}$; however, the duration of EMLA application was not clear. Depth of anesthesia to 1 to $2 \mathrm{~cm}$ has been described. ${ }^{64}$ When iontophoresis with 4 percent lidocaine and 1:50,000 epinephrine was used for minor surgical procedures, the type of lesion made no difference in efficacy of iontophoresis, although the size of the lesion and type of procedure did. Iontophoresis was 80 to 100 percent effective in injections, incisions, abrasions, laser surgery, and cautery. It was much less effective in excisions. Lesions greater than $1.0 \mathrm{~cm}$ were noted by physicians to have less pain relief, although patients noted little change. Iontophoresis was less effective on hands and feet. ${ }^{65}$

Complications have included prolonged erythema that resolved in 24 hours, tingling, burning, and pulling sensations that were especially apparent at the start of the current or if the amperage was turned up too rapidly. A metallic taste was noted when iontophoresis was used on the face. ${ }^{65}$ Cutaneous burns have also been reported. ${ }^{66}$

\section{Conclusions}

A number of new anesthetic methods can be used for a broad range of office procedures. These methods have proved to reduce pain and discomfort, and one would expect improved patient satisfaction. Although these newer developments have been used in other specialties, their application to family practice has not been tested extensively, and the full extent of their benefit has not been defined. Some methods are more complicated. If improved anesthesia results from simple buffering and warming of lidocaine, we can benefit our patients.

\section{References}

1. Larson PO, Ragi G, Swandby M, Darcey B, Polzin G, Cary P. Stability of buffered lidocaine and epinephrine used for local anesthesia. J Dermatol Surg Oncol 1991;17:411-4.

2. Moore DC. The $\mathrm{pH}$ of local anesthetic solutions. Anesth Analg 1981;60:833-4.

3. DiFazio CA, Carron H, Grosslight KR, Moscicki JC, Bolding WR, Johns RA. Comparison of $\mathrm{pH}$-adjusted lidocaine solutions for epidural anesthesia. Anesth Analg 1986;65:760-4.

4. Christoph RA, Buchanan L, Begalla K, Schwartz S. Pain reduction in local anesthetic administration through pH buffering. Ann Emerg Med 1988;17: 117-20.

5. Bartfield JM, Gennis P, Barbera J, Breuer B, Gallagher EJ. Buffered versus plain lidocaine as a local anesthetic for simple laceration repair. Ann Emerg Med 1990;19:1387-9.

6. Brogan GX Jr, Giarrusso E, Hollander JE, Cassara G, Maranga MC, Thode HC. Comparison of plain, 
warmed, and buffered lidocaine for anesthesia of traumatic wounds. Ann Emerg Med 1995;26:121-5.

7. Mader TJ, Playe SJ, Garb JL. Reducing the pain of local anesthetic infiltration: warming and buffering have a synergistic effect. Ann Emerg Med 1994; 23:550-4.

8. Bartfield JM, Ford DT, Homer PJ. Buffered versus plain lidocaine for digital nerve blocks. Ann Emerg Med 1993;22:216-9.

9. Bartfield JM, Homer PJ, Ford DT, Sternklar P. Buffered lidocaine as a local anesthetic: an investigation of shelf life. Ann Emerg Med 1992;21:16-9.

10. Farrell HA, Waldman SR, Campbell JP, Jones RO. Duration of buffered lidocaine versus unbuffered lidocaine: a double-blind, randomized prospective study. Ear Nose Throat J 1995;74:416-8.

11. Pryor GJ, Kilpatrick WR, Opp DR. Local anesthesia in minor lacerations: topical TAC versus lidocaine infiltration. Ann Emerg Med 1980;9:568-71.

12. Grant SA, Hoffman RS. Use of tetracaine, epinephrine, and cocaine as a topical anesthetic in the emergency department. Ann Emerg Med 1992;21: 987-97.

13. Ordog GJ, Ordog C. The efficacy of TAC (tetracaine, adrenaline, and cocaine) with various wound-application durations. Acad Emerg Med 1994;1:360-3.

14. Tipton GA, DeWitt GW, Eisenstein SJ. Topical TAC (tetracaine, adrenaline, cocaine) solution for local anesthesia in children: prescribing inconsistency and acute toxicity. South Med J 1989;82:1344-6.

15. Cannon CR, Chouteau S, Hutchinson K. Topically applied tetracaine, adrenaline, and cocaine in the repair of traumatic wounds to the head and neck. Otolaryngol Head Neck Surg 1989;100:78-9.

16. Smith SM, Barry RC: A comparison of three formulations of TAC (tetracaine, adrenaline, cocaine) for anesthesia of minor lacerations in children. Pediatr Emerg Care 1990;6:266-70.

17. Anderson AB, Colecchi C, Baronoski R, DeWitt TG. Local anesthesia in pediatric patients: topical TAC versus lidocaine. Ann Emerg Med 1990;19: 519-22.

18. Hegenbarth MA, Altieri MF, Hawk WH, Greene A, Ochsenschlager DW, O'Donnell R. Comparison of topical tetracaine, adrenaline, and cocaine anesthesia with lidocaine infiltration for repair of lacerations in children. Ann Emerg Med 1990;19:63-7.

19. Ernst AA, Crabbe LH, Winsemius DK, Bragdon R, Link R. Comparison of tetracaine, adrenaline, and cocaine with cocaine alone for topical anesthesia. Ann Emerg Med 1990;19:51-4.

20. White WB, Iserson KV, Criss E. Topical anesthesia for laceration repair: tetracaine versus TAC (tetracaine, adrenaline and cocaine). Am J Emerg Med 1986;4:319-22.

21. Bonadio WA, Wagner V. Efficacy of tetracaineadrenaline-cocaine topical anesthetic without tetracaine for facial laceration repair in children. Pedi- atrics 1990;86:856-7.

22. Schaffer DJ. Clinical comparison of TAC anesthetic solutions with and without cocaine. Ann Emerg Med 1985;14:1077-80.

23. Bonadio WA, Wagner V. Half-strength TAC topical anesthetic. For selected dermal lacerations. Clin $\mathrm{Pe}$ diatr Phila 1988;27:495-8.

24. Jacobson S. Errors in emergency practice. Emerg Med 1987;19:109.

25. Dailey RH. Fatality secondary to misuse of TAC solution. Ann Emerg Med 1988;17:159-60.

26. Wehner D, Hamilton GC. Seizures following topical application of local anesthetics to burn patients. Ann Emerg Med 1984:13:456-8.

27. Daya MR, Burton BT, Schleiss MR, DiLiberti JH. Recurrent seizures following mucosal application of TAC. Ann Emerg Med 1988;17:646-8.

28. Mofenson HC, Caraccio TR. Tack up a warning on TAC. Am J Dis Child 1989;143:519-20.

29. Tripp M, Dowd DD Jr, Eitel DR. TAC toxicity in the emergency department. Ann Emerg Med 1991; 20:106-7.

30. Dronen SC. Complications of TAC. Ann Emerg Med 1983;12:333.

31. Bonadio WA, Wagner V. When TAC drips into the eye. Am J Emerg Med 1990;8:371.

32. Barker W, Rodeheaver GT, Edgerton MT, Edlich RF. Damage to tissue defenses by a topical anesthetic agent. Ann Emerg Med 1982;11:307-10.

33. Martin JR, Doezema D, Tandberg D, Umland E. The effect of local anesthetics on bacterial proliferation: TAC versus lidocaine. Ann Emerg Med 1990; 19:987-90.

34. Terndrup TE, Walls HC, Mariani PJ, Gavula DP, Madden CM, Cantor RM. Plasma cocaine and tetracaine levels following application of topical anesthesia in children. Ann Emerg Med 1992;21:162-6.

35. Altieri M, Bogema S, Schwartz RH. TAC topical anesthesia produces positive urine tests for cocaine. Ann Emerg Med 1990;19:577-9.

36. Schilling CG, Bank DE, Borchert BA, Klatzko MD, Uden DL. Tetracaine, epinephrine (adrenaline), and cocaine (TAC) versus lidocaine, epinephrine, and tetracaine (LET) for anesthesia of lacerations in children. Ann Emerg Med 1995;25:203-8.

37. Ernst AA, Marvez-Valls E, Nick TG, Weiss SJ. LAT (lidocaine-adrenaline-tetracaine) versus TAC (tetracaine-adrenaline-cocaine) for topical anesthesia of face and scalp lacerations. Am J Emerg Med 1995; 13:151-4.

38. Evers H, von Dardel O, Juhlin L, Ohlsen L, Vinnars E. Dermal effects of compositions based on the eutectic mixture of lignocaine and prilocaine (EMLA). Studies in volunteers. Br J Anaesth 1985;57:9971005.

39. Engberg G, Danielson $K$, Henneberg S, Nilsson A. Plasma concentrations of prilocaine and lidocaine 
and methaemoglobin formation in infants after epicutaneous application of $5 \%$ lidocaine-prilocaine cream (EMLA). Acta Anaesthesiol Scand 1987;31: 624-8.

40. Jakobson B, Nilsson A. Methemoglobinemia associated with a prilocaine-lidocaine cream and trimethoprim-sulphamethoxazole. A case report. Acta Anaesthesiol Scand 1985;29:453-5.

41. Nilsson A, Engberg G, Henneberg S, Danielson K, $\mathrm{DeVerdier} \mathrm{CH}$. Inverse relationship between agedependent erythrocyte activity of methaemoglobin reductase and prilocaine-induced methaemoglobinaemia during infancy. Br J Anaesth 1990;64:72-6.

42. Thakur BK, Murali MR. EMLA cream-induced allergic dermatitis: a role for prilocaine as an immunogen. J Allergy Clin Immunol 1995;95:776-8.

43. Bjerring P, Arent-Nielsen L. Depth and duration of skin analgesia to needle insertion after topical application of EMLA cream. Br J Anaesth 1990;64:173-7.

44. Juhlin L, Evers H, Broberg F. A lidocaine-prilocaine cream for superficial skin surgery and painful lesions. Acta Derm Venereol 1980;60:544-6.

45. de Waard van der Spek FB, Oranje AP, Lillieborg S, Hop WC, Stolz E. Treatment of molluscum contagiosum using a lidocaine/prilocaine cream (EMLA) for analgesia. J Am Acad Dermatol 1990;23(4 Pt 1):685-8.

46. Rosdahl I, Edmar B, Gisslen H, Nordin P, Lillieborg S. Curettage of molluscum contagiosum in children: analgesia by topical application of a lidocaine/prilocaine cream (EMLA). Acta Derm Venereol 1988;68:149-53.

47. Hallén A, Ljunghall $K$, Wallin J. Topical anaesthesia with local anaesthetic (lidocaine and prilocaine, EMLA) cream for cautery of genital warts. Genitourin Med 1987;63:316-9.

48. Ljunghall $\mathrm{K}$, Lillieborg $S$. Local anaesthesia with a lidocaine/prilocaine cream (EMLA) for cautery of condylomata acuminata on the vulval mucosa. The effect of timing of application of the cream. Acta Derm Venereol 1989;69:362-5.

49. Rylander E, Sjoberg I, Lillieborg S, Stockman O. Local anaesthesia of the genital mucosa with a lidocaine/prilocaine cream (EMLA) for laser treatment of condylomata acuminata: a placebo-controlled study. Obstet Gynecol 1990;75:302-6.

50. Benini F, Johnston CC, Faucher D, Aranda JV. Topical anesthesia during circumcision in newborn infants. JAMA 1993;270:850-3.

51. Honnens de Lichtenberg M, Krogh J, Rye B, Miskowiak J. Topical anesthesia with eutetic mixture of local anesthetics cream in vasectomy: 2 randomized trials. J Urol 1992;147:98-9.
52. Premachandra DJ. Use of EMLA cream as an analgesic in the management of painful otitis externa. J Laryngol Otol 1990;104:887-8.

53. Raine NM, Whittet HB. EMLA cream and induced vertigo. Br J Hosp Med 1994;51:614-5.

54. Stow PJ, Glynn CJ, Minor B. EMLA cream in the treatment of post-herpetic neuralgia. Efficacy and pharmacokinetic profile. Pain 1989;39:301-5.

55. Taddio A, Nulman I, Goldbach M, Ipp M, Koren G. Use of lidocaine-prilocaine cream for vaccination pain in infants. J Pediatr 1994;124:643-8.

56. Fitzgerald M, Millard C, McIntosh N. Cutaneous hypersensitivity following peripheral tissue damage in newborn infants and its reversal with topical anesthesia. Pain 1989;39:31-6.

57. Larsson BA, Jylli L, Lagercrantz H, Olsson GL. Does a local anaesthetic cream (EMLA) alleviate pain from heel-lancing in neonates. Acta Anaesthesiol Scand 1995;39:1028-31.

58. Halperin DL, Koren G, Attias D, Pellegrini E, Greenberg $M$, Wyss $M$. Topical skin anesthesia for venous, subcutaneous drug reservoir and lumbar punctures in children. Pediatrics 1989;84:281-4.

59. Buckley MM, Benfield P. Eutectic lidocaine/prilocaine cream. A review of the topical anaesthetic/analgesic efficacy of a eutectic mixture of local anaesthetics (EMLA). Drugs 1993;46:126-51.

60. Juhlin L, Hagglund G, Evers H. Absorption of lidocaine and prilocaine after application of a eutectic mixture of local anesthetics (EMLA) on normal and diseased skin. Acta Derm Venereol 1989; 69:18-22.

61. Oshima T, Kashiki K, Toyooka H, Masuda A, Amaha K. Cutaneous iontophoretic application of condensed lidocaine. Can J Anesth 1994;41:677-9.

62. Greenbaum SS, Bernstein EF. Comparison of ion-" tophoresis of lidocaine with a eutectic mixture of lidocaine and prilocaine (EMLA) for topically administered local anesthesia. J Dermatol Surg Oncol 1994:20:579-83.

63. Irsfeld $S$, Klement $W$, Lipfert $P$. Dermal anesthesia: comparison of EMLA cream with iontophoretic local anesthesia. Br J Anaesth 1993;71:375-8.

64. Hamilton JG. Needle phobia: a neglected diagnosis. J Fam Pract 1995;41:169-75.

65. Maloney JM, Bezzant JL, Stephen RL, Petelenz TJ. Iontophoretic administration of lidocaine anesthesia in office practice. An appraisal. J Dermatol Surg Oncol 1992;18:937-40.

66. Zeltzer L, Regalado M, Nichter LS, Barton D, Jennings $S$, Pitt L. Iontophoresis versus subcutaneous injection: a comparison of two methods of local anesthesia delivery in children. Pain 1991;44:73-8. 